Politik Ekonomik Kuram 2019, Cilt 3(2), 214-232

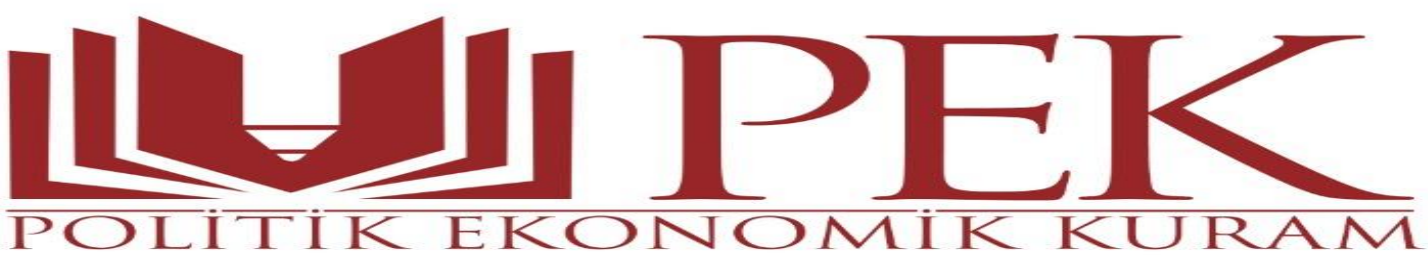

\title{
2008 Küresel Kriz Sonrası Uygulanan Para Politikası İle Enflasyon Arasındaki İlişkinin Ekonometrik Analizi ${ }^{1}$
}

Nagehan Karanfil ${ }^{2}$

Prof. Dr. İlhan Eroğlu ${ }^{3}$

\section{Makale Bilgileri}

Makale Geçmişi:

Makalenin Yüklendiği Tarih: 29.10.2019

Makalenin Kabul Edildiği Tarih: 03.12.2019

Anahtar Kelimeler: Fiyat İstikrarı, Küresel Kriz, ARDL

\footnotetext{
${ }^{1}$ Bu makale Nagehan Karanfil' in yürütmekte olduğu doktora tez çalışmasının bir kısmına dayanmaktadır.

${ }^{2}$ Gaziosmanpaşa Üniversitesi İktisadi ve İdari Bilimler Fakültesi İktisat Anabilim Dalı Doktora Öğrencisi nghnkrnfl@gmail.com/ 05386067686

${ }^{3}$ Gaziosmanpaşa Üniversitesi İktisadi ve İdari Bilimler Fakültesi İktisat Anabilim Dalı Öğretim Üyesi

İlhan.eroglu@gop.edu.tr / 05327769424
} 
Karanfil, N. Ve Eroğlu, İ. (2019), “2008 Küresel Kriz Sonrası Uygulanan Para Politikası İle Enflasyon Arasındaki İlişkinin Ekonometrik Analizi”, Politik Ekonomik Kuram, Cilt 3(2)

\title{
Özet
}

Bu çalışmada 2008 Küresel Krizi’nden sonra TCMB tarafından uygulanan para politikası ile enflasyon arasında yer alan ilişkinin incelenmesi amaçlanmıştır. 2010-2018 dönemine ait verileri kapsayan çalışmada bağımlı değişken olarak TÜFE (Tüketici Fiyat Endeksi), bağımsız değişkenler olarak EINF (beklenen enflasyon), MPS (para politikası duruşu), CUR (kapasite kullanım oranını), CGR (kredi genişlemesi), RER (reel döviz kuru) ve BD (bütçe açı̆̆ı) değişkenleri kullanılmıştır. Değişkenler arasında yer alan uzun dönem ve kısa dönem ilişkileri araştırmak için ARDL yöntemi kullanılmıştır. Analiz sonucunda bağımlı değişken enflasyon ile EINF, CUR, MPS ve BD değişkenleri arasında pozitif; CGR ve RER değişkenleri arasında ise negatif bir ilişki olduğu sonucuna ulaşılmıştır. Yapılan varyans ayrıştırması sonucunda ise beklenen enflasyon, kredi genişlemesi ve reel döviz kuru değişkenlerinin enflasyonu açıklama gücü en yüksek değişskenler olduğu görülmüştür.

\section{Econometric Analysıs Of The Relatıonshıp Between Monetary Polıcy And Inflatıon After 2008 Global Crisıs}

\begin{abstract}
The aim of this study is to investigate the relationship between monetary policy and inflation implemented by the CBRT after the 2008 Global Crisis. In the study covering data for 2010-2018 period TÜFE (consumer price index) as independent variable, EINF (expected inflation), MPS (monetary policy stance), CUR (capacity utilization rate), CGR (credit growth rate), RER (real exchange rate) and BD (budget deficit) used to as dependent variable. ARDL method was used to investigate long term and short term relationships between variables. As a result of the analysis, there was a positive the dependent variable is between inflation and EINF, CUR, MPS and BD variables positive, and a negative relationship between CGR and RER variables. As a result of the variance decomposition expected inflation, credit expansion and real exchange rate were the variables with the highest explanatory power for inflation.
\end{abstract}

Key Words: Price Stability, Global Crisis, ARDL 
Karanfil, N. Ve Eroğlu, İ. (2019), “2008 Küresel Kriz Sonrası Uygulanan Para Politikası İle Enflasyon Arasındaki İlişkinin Ekonometrik Analizi”, Politik Ekonomik Kuram, Cilt 3(2)

\section{Giriş}

Enflasyon denildiğinde, ekonomide yer alan mal ve hizmet fiyatlarının devamlı ve genel olarak bir artış göstermesi ifade edilmektedir. Birçok merkez bankası, enflasyonu kontrol etmek suretiyle ekonomide fiyat istikrarını sağlamaya çalışmaktadır (TCMB, 2013: 1).Enflasyonun yaşandığı bir ortamda üretim maliyetlerinde artış, yatırım kararlarında belirsizlik gibi birçok olumsuz etki meydana gelebilmektedir. Enflasyon oranın istikrarlı bir şekilde bir aralık içerisinde değişmesi sağlanarak fiyat istikrarının yakalanması ile, enflasyonist ortamın oluşturduğu olumsuz ekonomik gelişmelerin asgari düzeye inmesi amaçlanmaktadır (Altay vd., 2011: 3-4).

Bir ekonomide tüketim, yatırım ve tasarruf kararlarının verilmesi sırasında genel fiyat düzeylerindeki değişimleri dikkate almaya gerek duymadan ekonomik kararların verilmesini ifade eden fiyat istikrarı kavramı ekonomik istikrar için önemli bir koşul olarak kabul edilmektedir. Türkiye Cumhuriyet Merkez Bankası (TCMB)'nın da birincil amacı olan fiyat istikrarı sağlanamadığı takdirde ekonomik dengelerde bozulmalar başlayabilmektedir. Fiyat istikrarının sağlanamadığı bir ekonomide, tasarruf sahipleri ve yatırımcılar enflasyon risk primi talep ederek piyasalarda yüksek faizlerin oluşmasına neden olur. Uygulanan ekonomik politikalara güven ve sermaye piyasalarına erişim azalır, ekonominin uluslararası piyasalarda rekabet gücü zayıflar, iş gücü piyasaları etkin çalışamaz, gelir dağılımı bozulur. Ekonomik aktörler karar alma süreçlerinde geleceğe değil, geçmişe yönelik karar alma alışkanlığı kazanarak enflasyonda bir atalet oluşmasına neden olurlar (Kara ve Orak, 2008: 2).

Fiyat istikrarını sağlayabilmek için merkez bankalarının kullandığı temel araç faiz oranlarıdır (Doğan vd., 2016: 408). Ancak 2008 yılında yaşanan küresel kriz sonrası sadece fiyat istikrarını sağlamanın yeterli olmadığı, fiyat istikrarının yanı sıra finansal istikrarın da sağlanması gerektiği konusunda küresel platformlarda bir görüş birliği oluşmuştur. Fakat, merkez bankalarının tek bir para politikası aracı ile birden fazla değişkeni kontrol etmesinin, fiyat istikrarı ile finansal istikrarı sağlayabilecek faiz oranının aynı olmasının her zaman mümkün olamaması nedeni ile birden fazla politika aracının devreye girmesi gerekmiştir. Küresel kriz sonrası değişen para politikası uygulamaları ile birlikte Türkiye'de de yeni bir para politikası bileşimi uygulanmaya başlanmıştır. TCMB, makro finansal riskleri azaltabilmek amacı ile kısa vadeli sermaye girişlerini azaltmak ve kredi genişlemesini sınırlandırmak olmak üzere iki ara hedef belirlemiştir. $\mathrm{Bu}$ hedeflere ulaşabilmek için ise, politika faizinin yanı sıra zorunlu 
karşılıklar ve faiz koridoru para politikası araçları olarak kullanılmaya başlanmıştır (Başçı ve Kara, 2011:4).

Bu çalışmada, 2008 Küresel Krizi'nden sonra TCMB'nin uygulamış olduğu, fiyat istikrarından taviz vermeden aynı zamanda finansal istikrarı da sağlamaya yönelik uygulanan para politikası ile enflasyon arasındaki ilişkinin analiz edilmesi amaçlanmıştır. Çalışma, uygulanan yeni para politikası bileşiminde fiyat istikrarının sağlanması konusunda hangi politikaların öncelikle kullanılması gerektiği konusunda, politika yapıcılara yol gösterici olması yönü ile önem arz etmektedir.

$\mathrm{Bu}$ doğrultuda çalışmada öncelikle enflasyona neden olan etmenleri tartışan teoriler ve fiyat istikrarını sağlamaya yönelik stratejilerden bahsedilecektir. Sonrasında ise analizde kullanılan değişkenler ve enflasyon arasındaki ilişkiyi inceleyen literatüre yer verilip ekonometrik analize geçilecektir. Son olarak sonuç ve öneriler kısmına yer verilecektir.

\section{Enflasyon Teorileri ve Fiyat İstikrarını Sağlamaya Yönelik Stratejiler}

\section{Enflasyon teorileri}

Enflasyona neden olan etmenler farklı iktisadi düşünceler tarafindan farklı açılar ile yorumlanmaktadır. Klasik iktisatçıların bakış açısı Irwing Fisher tarafından miktar kuramı ile açıklanmaktadır. Bu kurama göre enflasyonun kaynağı para arzı miktarına bağlanmaktadır. Ekonomide yer alan mevcut para arzının artması, fiyatlar genel düzeyinde bir artışa neden olarak enflasyonun oluşmasına neden olacaktır. Piyasaya sürülen kağıt ve madeni paraların yanı sıra, bankalarda bulunan mevduatlar da para arzı kavramının içinde düşünüldüğünde, para arzında yapılan bir artış, faizlerde düşüşe neden olacak ve bu durum sonucunda bankalardan mevduatlar çekilerek harcamalar gerçekleşecektir (Taban ve Şengür, 2016:49).

Keynesyen iktisatçılar, enflasyonun kaynağı olarak tam istihdam düzeyinde olan bir ekonomide meydana gelen talep artışlarını göstermektedir. Bu teoride toplam arz pasif bir rol üstlenmekte ve enflasyonun nedeni reel kaynaklara bağlanmaktadır. Para arzındaki artışlar enflasyonun kaynağı değil, enflasyonu finanse eden bir olgudur. Para arzında meydan gelen artışlar doğrudan harcamaları etkilemez. Öncelikle faiz oranlarında düşüşe neden olmak suretiyle, yatırım harcamalarında artış ve sonuçta toplam talepte artışa neden olmaktadır. Toplam talepte meydan gelen artışlar, ekonomide tam istihdam gerçekleşene kadar üretimi artırır. Ancak tam istihdam seviyesinden sonra fiyatlar genel düzeyinde artış meydana gelerek enflasyon oluşmaktadır (Taban ve Şengür, 2016:49). 
Klasik miktar teorisinin yeniden bir yorumu olan monetarizme göre enflasyonun en başlica ve tek nedeni para arzında gerçekleşen artışlardır (Aktan, 2010: 179).Üretilen mal miktarına paralel olmadan sınırsız bir şekilde artırılan para arzı enflasyona neden olmaktadır ve dolayısıyla enflasyon parasal bir olgudur. Monetaristlere göre, enflasyona neden olmamak için para arzına gereksiz müdahalelerden kaçınılmalı ve sabit bir parasal kural belirlenerek, sabit oranda para arzı artışı gerçekleştirilmelidir (Orhan ve Erdoğan, 2008:277-278).

Yapısalcı yaklaşımda ise maliyet-itişli enflasyon teorisine göre değerlendirilmektedir. Söz konusu teori, arz yanlı bir olgudur. Ülkelere özgü yapısal faktörlere bağlı olduğu düşünülen enflasyon, özel kesimde birim maliyetleri ve kar unsurlarını değiştirmektedir. Yapısalcı yaklaşıma göre, ekonomideki mevcut sektörlerde toplam arzın toplam talebe geç uyum sağlaması durumunda, toplam talepte bir fazlalık oluşarak enflasyon meydana gelmektedir (Şahinoğlu vd., 2010:11).

\section{Fiyat istikrarını să̆lamaya yönelik stratejiler}

Para politikası uygulamasında, öncelikli amacın fiyat istikrarının sağlanması olması nedeni ile, zamanla farklı para politikası stratejileri oluşturulmuştur. Merkez bankaları tarafından fiyat istikrarı sağlanması konusunda fikir birliğgi olmasına rağmen, bu amaca ulaşmak için uygulanacak stratejiler konusunda görüş ayrılıkları bulunmaktadır. Geçmişten günümüze kadar uygulanmış olan bu stratejiler; parasal hedefleme, döviz kuru hedeflemesi ve enflasyon hedeflemesi olarak literatürde yer almaktadır (Takım, 2011:20).

Parasal hedefleme stratejisinde, parasal büyüklüğe dair yapılan artış oranı hedef olarak belirlenmektedir. Enflasyon oranlarına ilişkin beklentileri kontrol edebilmek amacı ile uygulanan bu stratejinin seçilme nedeni, para otoriteleri tarafından para arzı değişkenin kısa bir zaman zarfında yönetilebileceği düşüncesidir. Parasal büyüme kuralının etkili olduğu stratejiyi, klasik miktar teorisini temel alarak analiz edebilmek mümkün olmaktadır. Bu düşünceye temel oluşturan gerekçe ise, klasik miktar teorisinde para arzında yapılan artışın doğrudan bir şekilde fiyatlara yansıdığı görüşünün temel alınmasıdır (Erdoğan, 2005: 39-40).

Döviz kuru hedeflemesi stratejisi, ulusal paranın değeri başka bir ülkenin para birimine sabitlenmek suretiyle uygulanmaktadır. Ulusal paranın sabitleneceği ülke seçilirken dikkat edilen unsur düşük enflasyon yaşayan bir ülke olmasıdır. Bu sratejide sadece sabit kur rejimi değil, ayarlanabilir kur hedefi de uygulanabilmektedir. Dolayısıyla kur rejiminin sabit olarak belirlenmesi zorunlu olmamaktadır (Yiğitbaş, 2009: 209). 
Karanfil, N. Ve Eroğlu, İ. (2019), "2008 Küresel Kriz Sonrası Uygulanan Para Politikası İle Enflasyon Arasındaki İlişkinin Ekonometrik Analizi”, Politik Ekonomik Kuram, Cilt 3(2)

Enflasyon hedeflemesi stratejisinde, doğrudan bir şekilde enflasyon oranı hedeflenmektedir. Halkın enflasyona dair beklentilerini etkilemek suretiyle fiyat ve ücretlerin belirlenmesi amacı ile enflasyon oranı nominal çapa olarak seçilmektedir. Bu stratejide parasal otorite tarafından, politikalar belirlenirken sadece döviz kuru ya da parasal hedefler belirlenmez, para politikasına dair tüm araç ve bilgiler kullanılmaktadır (Kalaycı, 2002: 275; Akyazı ve Ekinci, 2009: 3).

\section{2008 Küresel Kriz Sonrası Uygulanan Para Politikası İle Enflasyon Arasındaki İlişkinin} Ekonometrik Analizi

Bu çalışmada 2008 Küresel Krizi'nden sonra TCMB'nin uygulamış olduğu para politikası ile enflasyon arasındaki ilişkinin ekonometrik olarak analiz edilmesi amaçlanmıştır. Analizde kullanılan değişkenler, ilgili literatür incelenerek belirlenmiştir.

\subsection{Literatür}

Konu ile ilgili literatüre bakıldığında enflasyona etki eden değişkenlerden bütçe açıklarının önemli bir inceleme konusu olduğu görülmektedir. Woodford (1994, 1995, 1996), Sims (1994, 1998) ve Canzoneri vd. (2001) çalışmalarında ifade edilen "Fiyat Düzeyinin Mali Teorisi" yaklaşımına göre, hükümetin bastığı borçlanma senetlerinin aldığı reel değer, cari ve gelecekte beklenen fazlaya dair bugün alacağı değere eşit olması gerekmektedir. Söz konusu bu eşitliğin maliye politikası ile sağlanamaması durumunda, fiyat düzeyinin bu dengeyi sağlayacağı ileri sürülmektedir. Fisher ve Easterly (1990) enflasyon ile bütçe açıkları arasında enflasyonun düşük seviyelere sahip olduğu dönemlerde zayıf, hiper enflasyonun yaşandığg zamanlarda ise güçlü bir ilişkinin olduğunu ifade etmektedirler. Çalışmaya göre emisyon yöntemi ile bütçe açıklarının finanse edilmesi enflasyonda artış ve reel vergi gelirlerinde düşüşe, sonuçta da bütçe açıklarına neden olmaktadır. Benzer bir sonuç Fisher vd. (2002) çalışmalarında elde edilmiştir. Çalışmada 94 gelişmiş ve gelişmekte olan ülke için yapılan analiz sonucunda enflasyon ve bütçe açıkları arasında, yüksek enflasyon yaşayan ülkelerde anlamlı bir bulguya ulaşılmıştır. Panel veri analizine göre yapılan çalışmada düşük enflasyon dönemlerinde değişkenler arasında zayıf bir ilişki olduğu görülmüştür. Lin ve Chu (2013) ARDL yöntemini kullanarak 91 ülke için yaptıkları çalışmada, yüksek enflasyonun yaşandığı ülkelerde bütçe açığının enflasyona etkisinin güçlü, düşük enflasyonun yaşandığı ülke gruplarında ise zayıf bir etkisi olduğunu ortaya koymuşlardır. Olodipo ve Akinbobola (2011) Nijerya için yaptıkları çalışmada bütçe açıklarının enflasyona neden olduğuna dair anlamlı sonuçlara ulaşmışlardır. Vieira (2000) Almanya, Hollanda, Belçika, İngiltere, Fransa ve İtalya’yı kapsayan Avrupa Birliği ülkeleri için 
Karanfil, N. Ve Eroğlu, İ. (2019), “2008 Küresel Kriz Sonrası Uygulanan Para Politikası İle Enflasyon Arasındaki İlişkinin Ekonometrik Analizi”, Politik Ekonomik Kuram, Cilt 3(2)

enflasyon ve bütçe açıkları arasındaki uzun dönemli ilişkiyi sınır testi tekniğini kullanarak analiz etmiştir. Analiz sonucunda İtalya ve Belçika'da uzun dönemli söz konusu ilişkinin pozitif, Fransa'da negatif olduğu bulgularına ulaşmıştır.

Doğru ve Şentürk (2013) az gelişmiş ve gelişmekte olan 19 Latin Amerika ülkesi ve Karayip ülkesi için bütçe açıkları ve enflasyon arasındaki ilişkiyi panel eş bütünleşme ve hata düzeltme modeli ile analizini yapmışlardır. Çalışma sonucunda değişkenler arasında uzun dönemde pozitif bir ilişki olduğu bulgusuna ulaşılmıştır. Oktayer (2010) Türkiye ekonomisine yönelik bütçe açıkları, para arzı artışı ve enflasyon arasında yer alan ilişkiyi inceldiği çalışmasında eşbütünleşme yöntemlerini kullanmıştır. Analiz sonucunda elde edilen bulgular, makro bir açıdan bakıldığında para miktarının fiyat düzeyini etkileyen ana unsur olmadığı, kamu borç stoku ve bütçe dengesi arasındaki ilişkiyi belirleyen bütçe kısıtının önemli bir etken olduğunu ortaya çıkarmıştır. Abdioğlu ve Terzi (2009) bütçe açı̆̆ı ve enflasyon arasındaki ilişkiyi Tanzi ve Patinkin etkileri yönüyle incelemişlerdir. ARDL yönteminin kullanıldığı analiz sonucunda iki değişken arasında uzun dönemde negatif bir ilişki olduğu Patinkin etkisinin Tanzi etkisine göre daha etkin olduğu görülmüştür. Özmen ve Koçak (2011) Türkiye'de 1994 ve 2011 dönemleri için yaptıkları çalışmada, bütçe açığı ve enflasyon arasında uzun dönemli bir ilişki elde edilememiştir. ARDL yöntemi kullanılarak elde edilen sonuç parasal görüşü destekler nitelik taşımaktadır. Altıntaş vd. (2008) Türkiye'de bütçe açığı, para arzı ve enflasyon arasındaki ilişkiyi ARDL sınır testi yöntemini kullanarak analiz etmişlerdir. 1992 ve 2006 dönemlerinin incelendiği çalışmanın sonucunda bütçe açıkları ve enflasyon arasında kısa ve uzun dönemde bir ilişkiye ulaşılamamıştır.

TCMB'nin özellikle 2008 sonrası uyguladığı para politikasında kredilerin önemli bir yeri bulunmaktadır. TCMB etkin bir para politikasını sağlayabilmek konusunda iletişimi kolaylaştırmak için krediler ve döviz kurunu ön plana çıkarmıştır. Özellikle finansal istikrarı içine alan yeni para politikasında tek başına politika faizinin yeterli olmayacağının anlaşılması üzerine, iletişimin krediler ve döviz kuru aracılığı ile yapılması, söz konusu değişkenlerin ayrı ayrı kanallarla etkilenmesini gerekli hale getirmiştir (Kara, 2012:7). Birinci (2011) yaptığ1 çalışmada enflasyonun kredi politikaları uygulanarak önlenebileceğini ifade etmektedir. Birinci (2011)'ye göre yüksek enflasyonun yaşandığı bir ekonomik ortamda, faiz oranlarını yükseltmek suretiyle yatırımları durdurma seçeneği spekülatif yatırımların yanı sıra diğer yatırımların da durmasına yol açabileceği nedeniyle, etkin olmayan bir para politikası uygulaması olabilmektedir. Böyle bir sonuca neden olmamak için faizleri yükseltmek yerine banka kredilerinin sınırlandırılması yolu ile yatırımların devam etmesi sağlanabilmektedir. Arslan ve 
Karanfil, N. Ve Eroğlu, İ. (2019), "2008 Küresel Kriz Sonrası Uygulanan Para Politikası İle Enflasyon Arasındaki İlişkinin Ekonometrik Analizi”, Politik Ekonomik Kuram, Cilt 3(2)

Yapraklı (2008) çalışmalarında banka kredileri ve enflasyon arasında bahsettiğimiz bilgileri destekler nitelikte sonuçlara ulaşmışlardır. Türkiye'de 1983-2007 dönemleri için Johansen eş bütünleşme ve hata düzeltme Granger nedensellik yöntemini kullanarak yaptıkları çalışmada, banka kredileri ile enflasyon arasında pozitif bir ilişki olduğunu tespit etmişlerdir. Çalışmaya göre, banka kredilerinde bir azalma iç talepte azalmaya neden olarak fiyatlarda yavaşlama, dolayısı ile enflasyonda düşüşü gerçekleştirdiği bulgusuna ulaşılmıştır. Geanakoplos ve Dubley (2009) kredi kartı kullanım sayısındaki artışın, Moinescu (2012) ise AB ülkeleri için panel veri analizini kullanarak yaptığı çalışmasında bireysel kredilerdeki artışın enflasyonun yükselmesine neden olabileceği sonuçlarına ulaşmışlardır. Asongu (2012) 34 Afrika ülkesi için regresyon analizini kullanarak yaptığı çalışmasında, kredi kullanımına sınırlamalar getiren önlemlerin enflasyonu düşürme konusunda başarılı sonuçlar verdiği bulgusuna ulaşmıştır. Ziramba (2008) ise Güney Afrika için kısıtsız hata düzeltme yöntemini kullanarak yaptığı analiz sonucunda genel literatürün tersi bir sonuç elde etmiş, banka kredilerinin enflasyon üzerinde anlamlı bir etkisinin olmadığı ancak dolaylı bir ilişki olduğunu ortaya çıkarmıştır. Yüksel ve Özsarı (2016) yaptıkları çalışmada da 1994-2015 dönemi için Johansen Eş Bütünleşme ve Toda Yamamoto yöntemlerini kullandıkları çalışmada bireysel kredilerde oluşan bir artışın enflasyon sorununa yol açmadığını ortaya koymuş ve enflasyon sorununun çözümü için bireysel kredilerde kısıtlamaya gidilmesi haricinde yöntemler aranması gerektiğini ifade etmişlerdir.

Yapraklı (2011) Türkiye'de 2006-2011 dönemi için hata düzeltme, geliştirilmiş Granger nedensellik yöntemini kullandığı çalışmasında döviz kurlarının enflasyon üzerinde negatif bir etkiye sahip olduğu sonucuna ulaşmıştır. Çalışmalarında döviz kuru kanalının enflasyonu etkileme gücünün yüksek olduğu, TCMB'nin para politikasını oluştururken kurların enflasyona olan etkisini dikkate alması gerektiğini belirtmektedirler. Selim ve Ayvaz (2014) 1990-2012 dönemini kapsayan Türkiye ekonomisi için yaptıkları analizde reel efektif döviz kurunun enflasyon üzerinde güçlü bir etkisi olduğu ve söz konusu dönem içerisinde yaşanan krizlerin önemli bir nedeni olduğunu ortaya koymuşlardır. Peker ve Görmüş (2008) vektör otoregresif yöntemi ile yaptıkları analizde Türkiye ekonomisinde fiyatlar genel düzeyinin kur şoklarına karşı duyarlılığının oldukça fazla olduğu sonucuna ulaşmışlardır. Özçiçek (2007) 1982-2002 dönemi için yaptıkları analizde kriz dönemlerinde kurların fiyatlar genel düzeyine geçişkenliğinin yükssek olduğu, bu yüksek geçişkenliğin krizlerden kaynaklandığı ve gerçek etkinin daha düşük olduğunu ve dolayısıyla enflasyonu düşürme politikalarının kur politikalarına bağımlılığın daha az olduğunu belirtmişlerdir. 
Karanfil, N. Ve Eroğlu, İ. (2019), "2008 Küresel Kriz Sonrası Uygulanan Para Politikası İle Enflasyon Arasındaki İlişkinin Ekonometrik Analizi”, Politik Ekonomik Kuram, Cilt 3(2)

\subsection{Model ve veri seti}

Çalışma Türkiye'de 2010-2018 dönemini kapsamaktadır. Analizde kullanılan değişkenlere ait zaman serileri TCMB EVDS, BDDK, Hazine ve Maliye Bakanllğı veri bankalarından elde edilmiştir. Değişkenlere ait aylık veriler kullanılmıştır. Dolayısıyla çalışma her bir değişken için 108 gözlemden oluşan veri setine dayanmaktadır. Çalışmada kullanılan değişkenler arasındaki fonksiyonel ilişkinin formel biçimi aşağıda gösterilmektedir:

$$
I N F=f(E I N F+M P S+C U R+C G R+R E R+B D)
$$

Modelde bağımlı değişken olan INF; TÜFE (Tüketici Fiyat Endeksini), bağımsız değişkenler EINF; beklenen enflasyonu, MPS; para politikası duruşunu, CUR; kapasite kullanım oranını, CGR kredi genişlemesini, RER; reel döviz kurunu ve BD; bütçe açığını simgelemektedir.

\subsection{Yöntem}

Modelde belirlenen değişkenlere ait tanımlayıcı istatistikler tablo 1'de yer almaktadır. Tablo 1'e göre serilerin tamamı normal dağılım göstermemektedir.

Tablo 1.Tanımlayıcı İstatistikler

\begin{tabular}{lccccccc}
\hline Değişkenler & INF & EINF & MPS & CUR & CGR & RER & BD \\
\hline Ortalama & 0,8 & 0,7 & 0,1 & 76,5 & 12400 & 0,4 & -28400 \\
Median & 0,6 & 0,6 & $-0,2$ & 76,8 & 11300 & 0,5 & -14500 \\
St Sapma & 1,0 & 0,4 & 1,5 & 1,8 & 61057 & 0,1 & 804000 \\
Çarpıklık & 1,6 & 0,9 & 2,5 & $-1,6$ & 0,5 & $-0,4$ & $-1,1$ \\
Basıkl1k & 10,1 & 4,0 & 11,9 & 7,3 & 2,2 & 2,2 & 4,3 \\
Jarque-Bera & $275,2^{*}$ & $17,7 *$ & $465,6^{*}$ & $125,0^{*}$ & $7,4^{*}$ & $6,2^{*}$ & $29,8^{*}$ \\
Olasılık & 0,0 & 0,0 & 0,0 & 0,0 & 0,0 & 0,0 & 0,0 \\
Gözlemler & 108 & 108 & 108 & 108 & 108 & 108 & 108 \\
\hline
\end{tabular}

Not: Jargeu-Bera normal dağılım test sonuçlarını vermektedir. Null hipotez: seriler normal dağılım gösterir biçimindedir. *Işsareti serilerin normal dağılıma sahip olmadığını göstermektedir.

Zaman serisi verileri ile yapılan analizlerde, kullanılan verilerin durağan olması gerekmektedir.

Verilerin durağan olmaması, sahte regresyona sebep olabilmekte ve değişkenler arasında var olan ilişkinin doğruluğu sorgulanabilmektedir. $\mathrm{Bu}$ nedenle verilerin öncelikle durağanlık sınaması yapılmakta, veriler durağan ise hangi derecede durağan oldukları AugmentedDickey Fuller (ADF) ve PhillipsPerron (PP) birim kök testlerisınanmaktadır (Yapraklı, 2011: 25). Çalışmamızda, modelde yer alan değişkenler arasında normal dağılım göstermeyen serilere durağanlık sınaması yapmak için Phillips Peron testi kullanılmıştır. 
Karanfil, N. Ve Eroğlu, İ. (2019), “2008 Küresel Kriz Sonrası Uygulanan Para Politikası İle Enflasyon Arasındaki İlişkinin Ekonometrik Analizi”, Politik Ekonomik Kuram, Cilt 3(2)

Tablo 2.Birim Kök Testleri

\begin{tabular}{|c|c|c|}
\hline Dönem & \multicolumn{2}{|c|}{ 2010-2018 } \\
\hline Yöntem & \multicolumn{2}{|c|}{ Phillips-Perron } \\
\hline Değişkenler & Düzey & 1.Sira Farklar \\
\hline INF & $-23.74865^{\star \star \star}$ & $-36.65686^{* \star \star}$ \\
\hline EINF & $-6.342430^{* * *}$ & $-23.74865^{* \star *}$ \\
\hline MPS & -1.689335 & $-8.345994^{* * *}$ \\
\hline CUR & $-4.260771^{\star * \star}$ & $-11.89585^{\star * *}$ \\
\hline CGR & 1.504654 & $-9.042031^{* * *}$ \\
\hline RER & -0.070826 & $-8.263426^{* * *}$ \\
\hline $\mathrm{BD}$ & $-16.29302^{* * *}$ & $-128.5543^{\star * *}$ \\
\hline
\end{tabular}

Not: PP testine göre serilerin durağanlığı sınanmıştır. ***, **, * simgeleri sırasıyla \% 1, \%5 ve \% 10 anlamlılık düzeyine göre null hipotezi reddedilerek serilerin durağan olduğunu öngören alternatif hipotezin kabul edildiğini göstermektedir. PP testi için kullanılan gecikme sayısını Eviews9.0 paket programının Schwarz kriterine göre otomatik olarak seçtiği kabul edilmiştir.

Tablo 2, PP birim kök test sonuçlarını göstermektedir. Tablo 2’ye göre, modelde yer alan bütün değişkenlerin birinci sıra farklarının \% 1 lanlamlılık düzeyinde durağan oldukları görülmektedir. Bir başka ifade ile birim kök içermemektedir. Değişkenlerin düzeyde durağanlık sınamalarında bakıldığında INF, EINF, CUR, BD değişkenlerinin \% 1 düzeyinde durağan oldukları sonucuna ulaşılmıştır. MPS, CGR ve RER değişkenlerinin ise birim kök içerdikleri yani durağan olmadıkları saptanmıştır.

Durağan olmayan serilerde sahte regresyona neden olması nedeni ile uzun dönemli dengeler araştırılırken önemli bilgiler görülemeyebiliyor. Bu sorunu ortadan kaldırabilmek için eş bütünleşme yöntemi kullanılmaktadır. Ancak, Engle ve Granger (1987), Johansen (1988) ve Johansen ve Juselius (1990) tarafından geliştirilen eş bütünleşme analizinin yapılabilmesi için bütün değişkenlerin düzeyde durağan olmamaları ve aynı derecede farkları alınması halinde durağan olmaları gerekmektedir. Söz konusu analizde, değişkenlerden bir veya daha fazlasının düzeyde durağan yani $\mathrm{I}(0)$ olması durumunda eş bütünleşme testi kullanılamaz. Bu sorunu ortadan kaldırmak için Pesaran vd. (2001) tarafindan geliştirilen ARDL (autoregressivedistributedlag) sınır testi yaklaşımı kullanılmaktadır. Sınır testi yaklaşımında değişkenlerin I(0) ya da I(1) olmasının bir önemi kalmamakta ve her iki durumda da değişkenler arasında eş bütünleşme ilişkisi araştırılabilmektedir (Karagöl vd., 2007: 75). Dolayısı ile 
tabloda gösterilen durağanlık sınamasının sonuçlarına bakıldığında çalışmamız için ARDL modelinin kullanılması uygun olacaktır.

ARDL sınır testi iki aşmadan oluşmaktadır. Öncelikle kısıtlanmamış hata düzeltme modeli (unrestrictederrorcorrection model UECM) kurulur. Eş bütünleşme ilişkisinin (uzun dönemli ilişki) bulunup bulunmadığını görebilmek için bağımlı ve bağımsız değişkenlerin gecikmelerine $\mathrm{F}$ testi uygulanır. $\mathrm{F}$ istatistiği, Pesaran tablo alt ve üst değerlerine göredeğerlendirilir. F değerinin alt sınırdan küçük olması eş bütünleşme ilişkisinin olmadığını, üst sınırın üzerinde olması eş bütünleşme ilişkisinin olduğunu gösterir. Söz konusu değerin alt ve üst sınırın arasında yer alması durumunda ise kesin bir değerlendirme yapılmaz ve diğer eş bütünleşme testleri uygulanır (Özmen ve Koçak, 2012: 7). İfade edilen bilgiler doğrultusunda UECM modelinin denklem olarak gösterimi aşağıdaki biçimdedir:

$$
\begin{aligned}
\Delta I N F_{t}=\alpha_{0}+ & \alpha_{1 i} \Delta E I N F_{t-i}+\alpha_{2 i} \Delta M P S_{t-i}+\alpha_{3 i} \Delta C U R_{t-i}+\alpha_{4 i} C G R_{t-i}+\alpha_{5 i} \Delta R E R_{t-i} \\
& +\alpha_{6 i} \Delta B D_{t-i}+E C T_{t-i}+\varepsilon_{t}
\end{aligned}
$$

Burada, $\Delta$ fark denklemini, $\alpha_{0} \ldots \alpha_{8}$ parametre değerlerini $\varepsilon$ hata terimini, ECT ise hata düzeltme terimini simgelemektedir. Diğer değişkenler yukarıda ifade edildiği şekildedir. Aşağıdaki tablo 3'te, tahmin denklemimizde yer alan değişkenler için hesaplanan $F$ testi sonuçları gösterilmektedir.

Tablo 3. F Testi Sonuçları

\begin{tabular}{lcc}
\hline \hline Test Statistic & Değer & $\mathrm{k}$ \\
\hline \hline F-Testi & 5.341986 & 8 \\
\hline \hline & & \\
Kritik Değerler & & \\
\hline \hline Anlamlılık & & \\
Düzeyleri & Alt Sınır & Üst Sınır \\
\hline \hline $10 \%$ & 1.85 & 2.85 \\
$5 \%$ & 2.11 & 3.15 \\
$2.5 \%$ & 2.33 & 3.42 \\
$1 \%$ & 2.62 & 3.77 \\
\hline \hline
\end{tabular}

Not: Sıfir $\left(\mathrm{H}_{0}\right)$ hipotezi uzun dönem ilişki yok biçimindedir. F testi değeri tablo da gösterilen kritik değerlerden büyük olduğu için alternatif hipotez $\left(\mathrm{H}_{1}\right)$ kabul edilmiştir. Burada k modelde yer alan değişken sayısını göstermektedir. Akaike, Schwarz, Hannan-Quinn kriterlerine göre gecikme uzunluğu 5 olarak hesaplanmıştır. 
Tablo 3'te F testi değerine bakıldığında değişkenler arasında eş bütünleşme-uzun dönem ilişkinin bulunduğu görülmektedir. Elde edilen bu sonuç ARDL modelin ikinci aşaması olan değişkenler arasındaki kısa dönemli ilişkilerin analizine geçmemize olanak sağlamaktadır. Aşağıdaki Tablo 4 ARDL modeli kullanılarak bulunan kısa dönem sonuçlarını göstermektedir.

Tablo 4. ARDL Model Kısa Dönem Bulguları

\begin{tabular}{crcrr}
\hline \hline Değişkenler & Katsayılar & Std. Hata & t-Statistic & Olasılık* \\
\hline \hline C & -0.041188 & 0.076183 & -0.540640 & 0.5901 \\
DINF(-3)** & 0.181973 & 0.067572 & 2.693003 & 0.0085 \\
DEINF(-2) ${ }^{\star * *}$ & 0.641208 & 0.166077 & 3.860908 & 0.0002 \\
DCGR(-1) & $-1.43 E-08$ & $1.78 \mathrm{E}-08$ & -0.801563 & 0.4250 \\
DCUR(-3) & 0.166393 & 0.086388 & 1.926123 & 0.0573 \\
DMPS(-7) & 0.388903 & 0.205743 & 1.890238 & 0.0620 \\
DRER & -4.058387 & 5.183563 & -0.782934 & 0.4358 \\
DBD(-4) & $1.89 E-10$ & $5.46 E-11$ & 3.455724 & 0.0008 \\
ECM(-1) & -0.768401 & 0.139569 & -5.505524 & 0.0000 \\
\hline \hline R-squared & 0.649321 & Mean dependent var & 0.002300 \\
Adjusted R-squared & 0.605486 & S.D. dependent var & 1.000667 \\
S.E. of regression & 0.628523 & Akaike info criterion & 2.021278 \\
Sum squared resid & 34.76362 & Schwarz criterion & 2.333899 \\
Log likelihood & -89.06391 & Hannan-Quinn criter. & 2.147801 \\
F-statistic & 14.81286 & Durbin-Watson stat & 2.005047 \\
Prob(F-statistic) & 0.000000 & & & \\
\hline \hline
\end{tabular}

Not: $* *, * * *$ işaretleri sırasıyla $\% 5$ ve $\% 1$ anlamlılık düzeylerini göstermektedir.

Tablo 4'ten elde edilen sonuçlara göre INF, EINF, CUR, MPS ve BD değişkenlerinin pozitif; CGR ve RER değişkenlerinin ise negatif bir ilişkide oldukları görülmektedir.

Merkez bankası para politikası uygulamalarında oluşabilecek belirsizlik, merkez bankasının para politikası uygulamalarında gösterdiği kararlı duruş ekonomide güven açısından önem taşımaktadır. Dolayısı ile merkez bankası tarafından uygulanan para politikalarına yönelik piyasada artan bir güvensizlik, enflasyona da yansıyarak enflasyonda bir artışa neden olabilmektedir. Enflasyon beklentilerine bakıldığında ise, enflasyona yönelik bekleyişlerde bir artış olması hem üreticiler hem de tüketiciler açısından enflasyonda artışa neden olabilmektedir. Gelecekte fiyatların yükseleceği beklentisi ile tüketiciler ve üreticiler maaş artışı, mal ve hizmet fiyatlarında artış, kiralarda artış gibi taleplerde bulunabilmektedirler. Söz konusu beklenti ve talepler gelecekte enflasyonun yükselmesine neden olarak enflasyonun kendisini doğrulaması olarak ifade edilen durumu ortaya çıkarabilmektedir. Dolayısı ile enflasyon beklentilerinde oluşacak bir artış enflasyonda da artışa neden olabilecektir. Tablo 4'e bakıldığında bütçe açığı ile enflasyon arasında pozitif bir ilişki görülmektedir. Bütçe açıklarının emisyon ile finanse 
edilmesi enflasyonda artışa neden olmakta ve enflasyondaki artış ise vergi gelirlerinin tahsilatındaki gecikme, vergi sistemindeki esneklik gibi nedenlerden dolayı vergi gelirlerinin reel değerini düşürerek bütçe açığının artmasına neden olabilmektedir. Literatürde Tanzi etkisi olarak bilinen enflasyon ve bütçe açığı arasındaki pozitif yönlü ilişki analiz sonucumuzu doğrulamaktadır. Kapasite kullanım oranının ekonomide doğal kapasitenin üzerine çıkması, talepte bir artışın göstergesi olması nedeni ile ayrıca marjinal maliyetlerin de yükselmesine neden olması dolayısı ile enflasyonda bir artışa sebep olabilmektedir. Tersi bir durumda, doğal kapasite sınırının altında olması halinde ise enflasyonda düşüş gerçekleşebilmektedir. Analizi içeren dönem için bu değişkeni değerlendirdiğimizde kapasite kullanım oranının altında veriler olsa da, zaman içerisinde verilerin artan bir seyir izlediğini görmekteyiz. Bu nedenle tablo da görülen enflasyon ve kapasite kullanım oranı arasındaki pozitif yönlü ilişki teori ile uyumlu bir sonuç vermektedir.

Reel döviz kurları ve kredi genişlemesi değişkenlerine ait analizde ortaya çıkan sonuç enflasyon ile negatif yönlü bir ilişki olduklarını göstermektedir. İktisadi teoriye göre, reel döviz kurlarında gerçekleşecek bir artışın, kurların maliyet nedeni ile fiyatlara geçişkenliği açısından bakıldığında enflasyonda bir artışa neden olması beklenmektedir. Ancak, analizimizde reel kurlara ait verilerin kullanıldığı dikkate alınacak olursa, nominalden farklı olarak reel kur düştükçe tl'nin değer kaybetmesine bağlı olarak enflasyonda bir artış yaşanabilmektedir. Benzer şekilde iktisadi teoriye kredi hacminde bir genişleme talep ve yatırımlarda artışa neden olarak enflasyonda da bir artışı meydana getirmektedir. İktisadi teoriye göre enflasyon ile reel döviz kurları ve kredi genişlemesi arasında kısa dönemde istatistiki olarak anlamlı ilişki yakalayamasak da varyans hesaplaması bulguları teoriyle uyumludur.

Çalışmanın devamında VAR modelinden elde edilen varyans ayrıştırma hesaplamaları yapılmıştır. Varyans ayrıştırma hesaplamaları modelde yer alan değişkenlerde meydana gelen değişmelerin kaynaklarını yüzde olarak ifade etmektedir. Değişkenlerde meydan gelecek bir değişmenin kendisinden ya da diğer değişkenlerden kaynaklı etkilerini ayrıştırarak oransal olarak yüzdelerini vermektedir. Eğer söz konusu değişme kendisinden kaynaklı şoklar ise, bu durumda etkinin dışsal kaynaklı olduğu söylenmektedir (Zengin, 2001:38).

Varyans ayrıştırma hesaplamaları yapılırken hipotez testlerinin doğruluğu açısından analizde kullanılan serilerin durağan olması gerekmektedir. Bu nedenle çalışmada varyans ayrıştırma hesaplamasında serilerin birinci sıra farklı alınarak analiz yapılmıştır. Varyans ayrıştırma hesaplamalarının sonuçları Tablo 5'te gösterilmektedir. 
Tablo 5.Varyans Ayrıștırma Hesaplamasının Sonuçları

\begin{tabular}{cccccccc}
\hline \hline Period & D(INF) & D(EINF) & D(CGR) & D(CUR & D(MPS) & D(RER) & D(BD) \\
& & & & & & & \\
\hline 1 & 100.00 & 0.00 & 0.00 & 0.00 & 0.00 & 0.00 & 0.00 \\
2 & 69.21 & 7.15 & 2.81 & 0.04 & 6.77 & 0.45 & 10.32 \\
3 & 55.39 & 18.53 & 2.22 & 0.04 & 7.89 & 0.36 & 12.84 \\
4 & 46.03 & 20.60 & 1.93 & 0.03 & 6.98 & 0.51 & 10.56 \\
5 & 44.45 & 19.02 & 2.22 & 0.62 & 6.71 & 0.58 & 12.58 \\
6 & 37.67 & 16.78 & 9.92 & 0.72 & 7.24 & 2.05 & 11.42 \\
7 & 34.18 & 16.64 & 11.11 & 2.68 & 8.06 & 1.69 & 13.36 \\
8 & 27.25 & 12.98 & 14.63 & 6.23 & 12.41 & 3.19 & 10.95 \\
9 & 25.00 & 12.01 & 17.25 & 5.44 & 10.82 & 2.94 & 9.61 \\
10 & 26.62 & 15.18 & 15.55 & 4.64 & 11.32 & 2.95 & 7.87 \\
11 & 26.92 & 14.46 & 14.77 & 4.41 & 12.20 & 4.01 & 7.45 \\
12 & 27.01 & 14.23 & 15.76 & 5.13 & 11.58 & 3.83 & 7.03 \\
13 & 28.60 & 12.82 & 18.80 & 6.72 & 9.73 & 3.34 & 7.00 \\
14 & 25.30 & 14.90 & 22.55 & 5.87 & 8.71 & 3.02 & 7.60 \\
15 & 24.32 & 13.99 & 21.63 & 6.79 & 8.38 & 2.70 & 9.29 \\
16 & 23.83 & 13.42 & 21.82 & 6.46 & 7.95 & 2.65 & 11.05 \\
17 & 23.08 & 12.80 & 22.86 & 6.48 & 7.72 & 2.94 & 10.83 \\
18 & 23.73 & 12.27 & 21.89 & 6.20 & 7.47 & 4.46 & 10.41 \\
19 & 23.23 & 12.03 & 21.82 & 6.38 & 7.64 & 4.45 & 10.65 \\
20 & 21.57 & 11.37 & 25.31 & 6.58 & 7.53 & 4.33 & 9.90 \\
21 & 20.42 & 11.28 & 24.83 & 6.25 & 9.17 & 6.00 & 9.37 \\
22 & 19.96 & 11.23 & 24.41 & 6.63 & 8.97 & 6.23 & 9.69 \\
23 & 19.65 & 11.07 & 23.98 & 7.06 & 8.80 & 6.18 & 10.53 \\
24 & 19.05 & 13.25 & 22.60 & 7.76 & 8.45 & 6.08 & 9.93 \\
25 & 18.24 & 14.78 & 22.96 & 7.55 & 8.01 & 6.56 & 9.48 \\
26 & 18.07 & 14.56 & 21.77 & 7.44 & 9.43 & 6.65 & 9.60 \\
27 & 17.11 & 13.86 & 24.34 & 7.05 & 8.92 & 6.33 & 9.10 \\
28 & 17.35 & 13.41 & 23.60 & 6.98 & 9.09 & 7.48 & 8.80 \\
29 & 17.75 & 13.45 & 23.36 & 6.91 & 8.91 & 7.44 & 8.87 \\
30 & 17.46 & 14.14 & 22.56 & 7.55 & 8.62 & 7.23 & 8.89 \\
31 & 18.03 & 13.65 & 22.47 & 8.35 & 8.27 & 6.94 & 8.77 \\
32 & 16.55 & 13.97 & 27.01 & 7.66 & 7.68 & 6.37 & 8.16 \\
\hline \hline
\end{tabular}

Kaynak: Tablodaki değerler "Varyans Hesaplaması Yöntemiyle” yazar tarafından hesaplanmıştır.

Tablo 5 sonuçlarına bakıldığında ilk aylarda \% 69 ve \% 55 gibi yüksek oranlar enflasyonun nedeninin kendisinden kaynaklandığı yani enflasyonun güçlü bir atalet kazandığı göstermektedir. Enflasyon ataletini beklenen enflasyonda da görebilmekteyiz. Enflasyona etki eden değişenlerden en yüksek oranların beklenen enflasyon ve kredi genişlemesi değişkenlerine ait olduğu ve zaman dilimi arttıkça enflasyondaki değişmeyi en fazla açıklama gücüne sahip değişkenin kredi genişlemesi olduğu görülmektedir. Benzer şekilde zaman diliminin artması ile 
enflasyondaki değişmeyi açıklama gücü artan bir diğer önemli değişkenin de reel kur olduğu görülmektedir.

\section{Sonuç}

Fiyat istikrarı kavramı ekonomide tüketim, yatırım ve tasarruf kararlarının verilmesinde önemli bir koşul olarak kabul görmektedir. Türkiye Cumhuriyet Merkez Bankası (TCMB)'nın da birincil amacı olan fiyat istikrarı sağlanamadığı takdirde ekonomik dengelerde bozulmalar başlayabilmektedir. Fiyat istikrarını sağlayabilmek için merkez bankalarının kullandığı temel araç faiz oranlarıdır. Ancak 2008 yılında yaşanan küresel kriz sonrası sadece fiyat istikrarını sağlamanın yeterli olmadığı, fiyat istikrarının yanı sıra finansal istikrarın da sağlanması gerektiği konusunda küresel platformlarda bir görüş birliği oluşmuştur. Fakat, merkez bankalarının tek bir para politikası aracı ile birden fazla değişkeni kontrol etmesinin, fiyat istikrarı ile finansal istikrarı sağlayabilecek faiz oranının aynı olmasının her zaman mümkün olamaması nedeni ile birden fazla politika aracının devreye girmesi gerekmiştir. Küresel kriz sonrası değişen para politikası uygulamaları ile birlikte Türkiye'de de yeni bir para politikası bileşimi uygulanmaya başlanmıştır.

Bu çalışmada, 2008 Küresel Krizi'nden sonra TCMB'nin uygulamış olduğu, fiyat istikrarından taviz vermeden aynı zamanda finansal istikrarı da sağlamaya yönelik uygulanan para politikası ile enflasyon arasındaki ilişkinin analiz edilmesi amaçlanmıştır. Çalışma, uygulanan yeni para politikası bileşiminde fiyat istikrarının sağlanması konusunda hangi politikaların öncelikle kullanılması gerektiği konusunda, politika yapıcılara yol gösterici olması yönü ile önem arz etmektedir.

2010-2018 dönemine ait verileri kapsayan çalışmada bağımlı değişken olarak TÜFE (Tüketici Fiyat Endeksi), bağımsız değişkenler olarak EINF (beklenen enflasyon), MPS (para politikası duruşu), CUR (kapasite kullanım oranını), CGR (kredi genişlemesi), RER (reel döviz kuru) ve BD (bütçe açı̆̆ı) değişkenleri kullanılmıştır. Değişkenler arasında yer alan uzun dönem ve kısa dönem ilişkileri araştırmak için ARDL yöntemi kullanılmıştır.

Analiz sonucunda bağımlı değişken enflasyon ile EINF, CUR, MPS ve BD değişkenleri istatistiki olarak anlamlı ve pozitif bir ilişkiye sahipken; enflasyon ile CGR ve RER değişkenleri arasında negatif yönlü bir ilişki bulunmasına rağmen istatistiki olarak anlamlı bir ilişki bulunamamıştır. Ancak Yapılan varyans ayrıştırması sonucunda ise beklenen enflasyon, kredi genişlemesi ve reel kur değişkenlerinin enflasyonu açıklama gücü en yüksek değişkenler olduğu görülmüştür. 
Karanfil, N. Ve Eroğlu, İ. (2019), "2008 Küresel Kriz Sonrası Uygulanan Para Politikası İle Enflasyon Arasındaki İlişkinin Ekonometrik Analizi”, Politik Ekonomik Kuram, Cilt 3(2)

\section{Kaynakça}

Abdioğlu, Z. ve Terzi, H., 2009. Enflasyon ve Bütçe Açıkları İlişkisi: Tanzi ve Patinkin Etkisi. Atatürk Üniversitesi İktisadi ve İdari Bilimler Dergisi, 23(2), 195-211.

Aktan, C. C., 2010. Monetarizm ve Rasyonel Beklentiler Teorisi, Ekonomi Bilimleri Dergisi, 2(1), 168-187.

Akyazı, H. ve Ekinci, A., 2009. Enflasyon Hedeflemesi, Büyüme ve Türkiye Cumhuriyet Merkez Bankası. Bankacılar Dergisi, 68, 3-19.

Altay, B., Tuğcu, C. T. ve Topçu, M., 2011. İşsizlik ve Enflasyon Oranları Arasındaki Nedensellik İlişkisi: G8 Ülkeleri Örneği. Afyon Kocatepe Üniversitesi İ̈BF Dergisi, 13(2), 1-26.

Altıntaş, H., Çetintaş, H. ve Taban, S., 2008. Türkiye'de Bütçe Açı̆̆ı, Parasal Büyüme ve Enflasyon Arasındaki İlişkinin Ekonometrik Analizi: 1992-2006. Anadolu Üniversitesi Sosyal Bilimler Dergisi, 8(2), 185-208.

Arslan, İ. ve Yapraklı, S., 2008. Banka Kredileri ve Enflasyon Arasındaki İlişki: Türkiye Üzerine Ekonometrik Bir Analiz (1983-2007). İstanbul Üniversitesi İktisat Fakültesi Ekonometri ve Ístatistik Dergisi, 7, 88-103.

Asongu, S. A., 2012. Financial Determinants of Consumer Price Inflation. What Do Dynamics in Money, Credit, Efficiency and Size Tell Us?. African Governance and Development Institute, AGDI Working Paper, WP/12/019, 1-25.

Başçı, E. ve Kara, H., 2011. Finansal İstikrar ve Para Politikası. Türkiye Cumhuriyet Merkez Bankası Çalışma Tebliği, No:11/08, , Mayıs 2011.

Birinci, Y., 2011. Enflasyon, Para Politikası Stratejileri. İstanbul Üniversitesi İktisat Fakültesi Mecmuasl, 47(1-4), 19-30.

Canzoneri, M.,Cumby, R. ve Diba, B., 2001. Is The Price Level Determined by the Needs of Fiscal Solvency?. American Economic Review, 91(5), 1221-1238.

Doğan, B., Eroğlu, Ö. ve Değer, O., 2016. Enflasyon ve Faiz Oranı Arasındaki Nedensellik İlişkisi: Türkiye Örneği. Çankırı Karatekin Üniversitesi İktisadi ve İdari Bilimler Fakültesi Dergisi, 6(1), 405-425.

Doğru, B. ve Şentürk, S. H., 2013. Latin Amerika Ülkelerinde Bütçe Açı̆̆ı ve Enflasyon Arasındaki Eş bütünleşme İlişkinin Analizi. Erciyes Üniversitesi İktisadi ve İdari Bilimler Fakültesi Dergisi, 41, 89-109.

Engle, R. F. ve Granger, C. W. J., 1987. Co-integration and error correction representation, estimation and testing. Econometrica, 55 (2): 251-276. 
Karanfil, N. Ve Eroğlu, İ. (2019), "2008 Küresel Kriz Sonrası Uygulanan Para Politikası İle Enflasyon Arasındaki İlişkinin Ekonometrik Analizi”, Politik Ekonomik Kuram, Cilt 3(2)

Erdoğan, S., 2005. Alternatif Para Politikası Stratejileri Üzerine Karşılaştırmalı Bir Değerlendirme. Kocaeli Üniversitesi Sosyal Bilimler Enstitüsü Dergisi, 9(1), 34-54.

Fischer, S.,Sahay, R. ve Végh, C. A., 2002. Modern Hyper-and High Inflations. NBER Working Paper Series, No.8930, 1-43.

Fisher, S. ve Easterly, W., 1990. The Economics of the Government Budget Constraint. The World Bank Research Observer, 5(2), 127-142.

Geanakoplos, J. ve Dubey, P., 2010. Credit Cards and Inflation. Games and Economic Behaviour, 70, 325-353.

Johansen, S., 1988. Statistical analysis of cointegration vectors. Journal of Economic Dynamics and Control, 12(2/3): 231-254.

Johansen, S. ve Juselius, K., 1990. Maximum likelihood estimation and inference on cointegration-with applications to the demand for Money. Oxford Bulletin of Economics and Statistics, 52(2): 169-210.

Kalayc1, Ş., 2002. Parasal Hedefleme, Enflasyon Hedeflemesi ve Enflasyonist Bekleyişler: Türkiye Ekseninde Bir Değerlendirme. Süleyman Demirel Üniversitesi İktisadi ve İdari Bilimler Fakültesi Dergisi, 7(2), 271-284.

Kara, H., 2012. Küresel Kriz Sonrası Para Politikası. TCMB Çalışma Tebliği, No.12/17.

Kara, H. ve Orak, M., 2008. Enflasyon Hedeflemesi. Türkiye Cumhuriyet Merkez Bankası Araştırma ve Para Politikası Genel Müdürlüğü.

Karagöl, E., Erbaykal, E. ve Ertuğrul, H. M., 2007. Türkiye'de Ekonomik Büyüme ile Elektrik Tüketimi İlişkisi: Sınır Testi Yaklaşımı. Doğuş Üniversitesi Dergisi, 8(1), 72-80.

Lin, H. ve Chu, H., 2013. Are Fiscal Deficits Inflationary?. Journal of International Money and Finance, 32, 214-233.

Moinescu, B. G., 2012. Credit Flow, Output Gapand Inflation: Nominal Convergence Challenges fort he EU New Member States. Journal of Applied Quantitative Methods, 7(4), 1-10.

Oktayer, A., 2010. Türkiye'de Bütçe Açığı, Para Arzı ve Enflasyon İlişkisi. Maliye Dergisi, $158,431-447$.

Oladipo, S. O. ve Akinbobola, T. O., 2011. Budget Deficit and Inflation in Nigeria: A Causal Relationship. Journal of Emerging Trends in Economics and Management Sciences, 2(1), 1-8.

Orhan, O. ve Erdoğan, S., 2008. Para Politikası. Yazıt Yayın-Dağıtım. Ankara: 4. Baskı. 
Özçiçek, Ö., 2007. Türkiye'de Ekonomik Krizler ve Döviz Kuru Enflasyon İlişkisi. Gazi Üniversitesi İktisadi ve İdari Bilimler Fakültesi Dergisi, 9(1), 71-80.

Özmen, M. ve Koçak, F. İ., 2012. Enflasyon, Bütçe Açığı ve Para Arzı İlişkisinin ARDL yaklaşımı ile Tahmini: Türkiye Örneği. Çukurova Üniversitesi İ̈BF Dergisi, 16(1), 119.

Peker, O. ve Görmüş, Ş., 2008. Türkiye'de Döviz Kurunun Enflasyonist Etkileri. Süleyman Demirel Üniversitesi İktisadi ve İdari Bilimler Fakültesi Dergisi, 13(2), 187-202.

Pesaran, M. H., Shin, Y. ve Smith, R. J., 2001. Bound Testing Approaches to the Analysis of Level Relationships. Journal of Applied Econometrics. 16 (3): 289-326.

Selim, S. ve Ayvaz Güven, E. T., 2014. Türkiye'de Döviz Kuru, Enflasyon ve İşsizlik Arasındaki İlişkinin Ekonometrik Analizi. Ekonomik ve Sosyal Araştırmalar Dergisi, $10(1), 127-145$.

Sims, C. A., 1994. A Simple Model for Study of the Determination of the Price Level and the Interaction of Monetary and Fiscal Policy. Economic Theory, 4(3), 381-399.

Sims, C. A., 1998. Econometric Implications of the Government Budget Constraint. Journal of Econometrics, 83, 9-19.

Şahinoğlu, T., Özden, K. Başar, S. ve Aksu, H., 2010. Türkiye'de Enflasyonun Oluşumu: ARDL Yaklaşımı. Sosyo Ekonomi Dergisi, 1: 28-46.

Taban, S. ve Şengür, M., 2016. Türkiye'de Enflasyonun Kaynağının Belirlenmesine Yönelik Ekonometrik Bir Analiz. Erciyes Üniversitesi Iktisadi ve İdari Bilimler Fakültesi Dergisi, 47, 47-64.

Takım, A., 2011. Türkiye'de Para Politikası Stratejilerinin Fiyat İstikrarına Etkisi: Enflasyon Hedeflemesi Örneği. ZKÜ Sosyal Bilimler Dergisi, 7(13), 15-35.

Türkiye Cumhuriyet Merkez Bankası, 2013. Enflasyon ve Fiyat İstikrarı.

Vieira, C., 2000. Are Fiscal Deficits Inflationary? Evidence fort he EU. Economic Research Paper, 7, 1-16.

Woodford, M., 1994. Monetary Policy and Price-Level Determinacy in a Cash-in-Advance Economy. Economic Theory, 4, 345-380.

Woodford, M., 1995. Price Level Determinacy Without Control of a Monetary Aggragate. NBER Working Paper Series, No. 5204, August, 1-40.

Woodford, M., 1996. Control of the Public Debt: A Requirement for Price Stability?. NBER Working Paper Series, No. 5684, July. 1-35. 
Karanfil, N. Ve Eroğlu, İ. (2019), "2008 Küresel Kriz Sonrası Uygulanan Para Politikası İle Enflasyon Arasındaki İlişkinin Ekonometrik Analizi”, Politik Ekonomik Kuram, Cilt 3(2)

Yapraklı, S., 2011. Açık Enflasyon Hedeflemesi Döneminde Parasal Aktarım Mekanizmasının Döviz Kuru Kanalı: Türkiye Üzerine Ekonometrik Bir Analiz. İstanbul Üniversitesi Iktisat Fakültesi Ekonometri ve İstatistik Dergisi, 15, 15-37.

Yiğitbaş, Ş., 2009. Gelişen Piyasa Ekonomilerinde Alternatif Para Politikası Stratejileri, Türkiye Ekonomisi Açısından Bir Değerlendirme. Celal Bayar Üniversitesi İIBF Yönetim ve Ekonomi Dergisi, 16(1), 207-225.

Yüksel, S. ve Özsarı, M., 2016. Türkiye'de Bireysel Krediler ile Enflasyon ve Cari İşlemler Açı̆̆ı Arasındaki Iedensellik İlişkisinin İncelenmesi, EconWorld2016@ImperialCollegeProceedings, London, UK. 10-12 August.

Zengin, A., 2001. Reel Döviz Kuru Hareketleri ve Dış Ticaret Fiyatları (Türkiye Ekonomisi Üzerine Amprik Bulgular). C. Ü. İktisadi ve İdari Bilimler Dergisi, 2(2), 27-41.

Zirambe, E., 2008. Bank Lending, Expenditure Components and Inflation in South Africa: Assessment from Bounds Testing Approach. South African Journal of Economic and Management Sciences, 11(2), 217-228. 